•保护论坛・

\title{
基于保护地役权的自然保护地适应性管理方法 探讨：以钱江源国家公园体制试点区为例
}

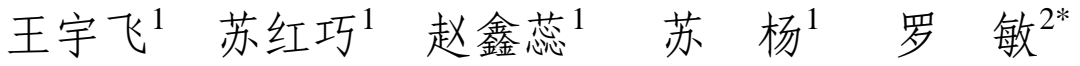 \\ 1 (国务院发展研究中心, 管理世界杂志社, 北京 100026) \\ 2 (环境保护杂志社, 北京 100062)
}

\begin{abstract}
摘要: 我国的自然保护地普遍存在着科学管控难、统一管理难和资金供给难等问题, 即便是国家公园体制试点区 也不例外。本文以钱江源国家公园体制试点区为例，设计了基于细化保护需求的保护地役权制度，以探索一种能 解决上述问题并能体现生态补偿的适应性管理方法, 包括: 细化主要保护对象的管理需求, 结合土地利用类型, 确定实施保护地役权的空间范围; 辨析保护需求和原住民生产、生活之间的关系, 形成正负行为的准则并以行为 清单的形式体现; 从生态系统监测指标改善情况、正负行为遵守情况和社区能力建设三个维度制定地役权制度的 评价方法; 据此形成地役权合同, 明确供役地人和需役地人的权责利, 形成考虑保护绩效的生态补偿方案。这种方 法可以解决自然保护地因为权属不一致造成的生态系统和景观破碎化问题, 缓解社区发展和生态保护之间的矛 盾, 在我国南方集体林地占比较高的自然保护地具有适用性。
\end{abstract}

关键词: 生态补偿; 适应性管理; 保护地役权; 自然保护地; 国家公园

\section{Conservation easement-inspired adaptive management methods for natural protected areas: A case study on Qianjiangyuan National Park pilot}

\author{
Yufei Wang ${ }^{1}$, Hongqiao $\mathrm{Su}^{1}$, Xinrui Zhao ${ }^{1}$, Yang $\mathrm{Su}^{1}$, Min $\mathrm{Luo}^{2 *}$ \\ 1 Management World Magazine, Development Research Center of the State Council, Beijing 100026 \\ 2 Environmental Protection Magazine, Beijing 100062
}

\begin{abstract}
It is difficult to carry out highly effective management in the natural protected areas of China due to complicated land ownership and lack of scientific research, especially in the National Park pilots. This paper proposes a conservation easement policy based on focused conservation needs by integrating an innovative adaptive management method and an ecological compensation plan, using the Qianjiangyuan National Park pilot as an example. First, the major conservation needs of the ecosystem elements are refined by determining the spatial scope of the easement implementation according to the land type. Secondly, the relationship between conservation need and the livelihood of local residents is clarified to form the classified conservation list. The evaluation method for easement is designed in three dimensions: improvement of monitoring indicators of the ecosystem, compliance with positive and negative actions and community capacity cultivation. Finally, the easement contract is formed by outlining the clear rights and responsibilities of the easement donor and donee. A scientific and flexible plan for ecological compensation is also carried out. This method can effectively solve the problem of land resource fragmentation at both on the ecosystem and landscape scale, which is normally caused by inconsistent ownership, as well as the conflict between community development and ecological conservation. Finally, this plan can be applied to the natural protected areas in southern China where the collective forest coverage is relatively high.
\end{abstract}

Key words: ecological compensation; adaptive management; conservation easement; natural protected areas; national park 
我国相当数量的自然保护地科研基础不够、土 地权属复杂、财政支持缺乏，存在科学管控难、统 一管理难和资金供给难的共性问题。现有的自然保 护地基本采用要素式的管理模式，即其管理目标并 非从整个生态系统的完整性角度出发, 而是关注生 态系统的某一个片段或者要素(苏杨等, 2018)。一个 自然生态系统内经常有多个不同类型的保护地, 这 种管理模式导致“一地多牌多主”、不同类型的保护 地交叉重叠、管理机构权责不清的现象普遍存在。 为了改善上述情况, 加强对生态系统的原真性和完 整性的保护，我国先后提出建立国家公园体制和构 建以国家公园为主体的自然保护地体系的目标。今 后我国自然保护地的管理将会由以资源要素为核 心的管理模式转向以生态系统为核心的管理模式。 国家公园体制也将引领自然保护地体系改革, 其先 行先试具有全国性的示范意义。生态系统的复杂 性、动态性、模糊性和干扰的不确定性, 决定了生 态系统管理目标、生态系统对管理行为的响应、管 理决策等方面的不确定性(杨荣金等, 2004)。适应性 管理作为一种应对复杂动态系统不确定性难题的 工具, 逐渐成为被认可的生态系统管理模式, 应用 于渔业管理、森林管理、流域生态治理与恢复等领 域(侯向阳等, 2011)。本研究主要从体制层面探讨如 何在国家公园通过适应性管理解决上述问题。

为此, 在问题导向下研究设计了符合我国国情 的保护地役权制度, 并率先应用于国家公园体制试 点区以实现适应性管理, 即: 明确保护对象, 细化 管理需求, 确定保护对象和原住民的生产、生活行 为之间的关系, 辨识原住民禁止、限制和鼓励的行 为, 形成正负行为清单并配套不同类型的激励方式; 据此来约束土地利用的方式和强度, 以地役权合同 的形式平衡保护与发展之间的关系。

传统的地役权是指为了利用自己土地的便利, 而对他人的土地进行一定程度的利用或者对他人 行使土地的权力进行限制的权利。随着社会的发展, 地役权已经在最初强调有利、相邻的私益性的基础 上增加了公益性，在土地利用和环境保护方面起到 了积极作用, 即保护地役权。美国2000年颁布的《第 三次财产法重述: 役权》(Restatement of Property, Third, Servitudes)中指出, 保护地役权的目标包括但 不局限于: 保留或保护不动产的自然、景观、开放 空间价值; 保障其农业、林业、休闲游㮩或开放空
间利用等功能; 保护或管理自然资源的利用; 保护 野生生物; 维系并提升土地、大气和水环境质量(唐 孝辉，2014)。本研究旨在借鉴国际经验的基础上, 寻求构建适合我国自然保护地现状的保护地役权 制度，与生态补偿结合并进行适应性管理，以解决 生态系统尺度和景观尺度上连续的自然保护地因 为权属不一致造成的破碎化管理问题，解决社区发 展和生态保护之间的矛盾。

\section{制度设计的技术路线和方法}

本研究技术路线基于自然保护地管理的问题 导向和国家公园体制建立的目标导向而提出。问题 导向主要是指能够解决生态系统和生物多样性保 护存在的客观问题，比如人为干扰造成的物种栖息 地保护不利、生态系统服务功能下降等; 目标导向 是指制度设计要符合《关于健全生态保护补偿机制 的意见》和《建立国家公园体制总体方案》(以下简 称《总体方案》)的要求。其中, 制度设计要以生态 系统科学管控的理论和社区利益诉求为基础，需围 绕保护目标, 平衡保护和发展的关系, 形成适应性 管理办法, 并制定有针对性的、精细化的补偿测算 方式和市场化、多元化的生态补偿模式。

\section{1 适应性管理框架的构建}

适应性管理框架是一种基于学习决策的资源 管理框架(Williams et al，2011)，主要包括界定问 题、编制方案、执行方案、检测、评估结果和改进 管理(Murray \& Marmorek, 2004)。它广泛应用于森 林等自然资源的管理(叶功富等, 2015; Birgé et al, 2016)。何思源等( 2017)从理论上设计了一套新型的 适应性管理框架，提出对重点保护对象的状态划分 空间等级，在特定的空间范围制定保护需求清单， 并配套保护地役权制度促进管制措施落地，但是 研究结论有待实践。本研究将其和生态补偿制度相 结合, 并应用于国家公园, 更新了上述适应性管理 框架(如图1所示)。其中，制度设计的基本原则要遵 循保护生物学理论, 比如保护珍贵物种优先、就地 保护原则等(马克平, 2009)。

\section{2 生态补偿的制度设计}

2016年国务院办公厅颁发的《关于健全生态保 护补偿机制的意见》提出要建立生态环境损害赔 偿、生态产品市场交易与生态保护补偿协同推进生 态环境保护的机制。结合《总体方案》中“构建市 


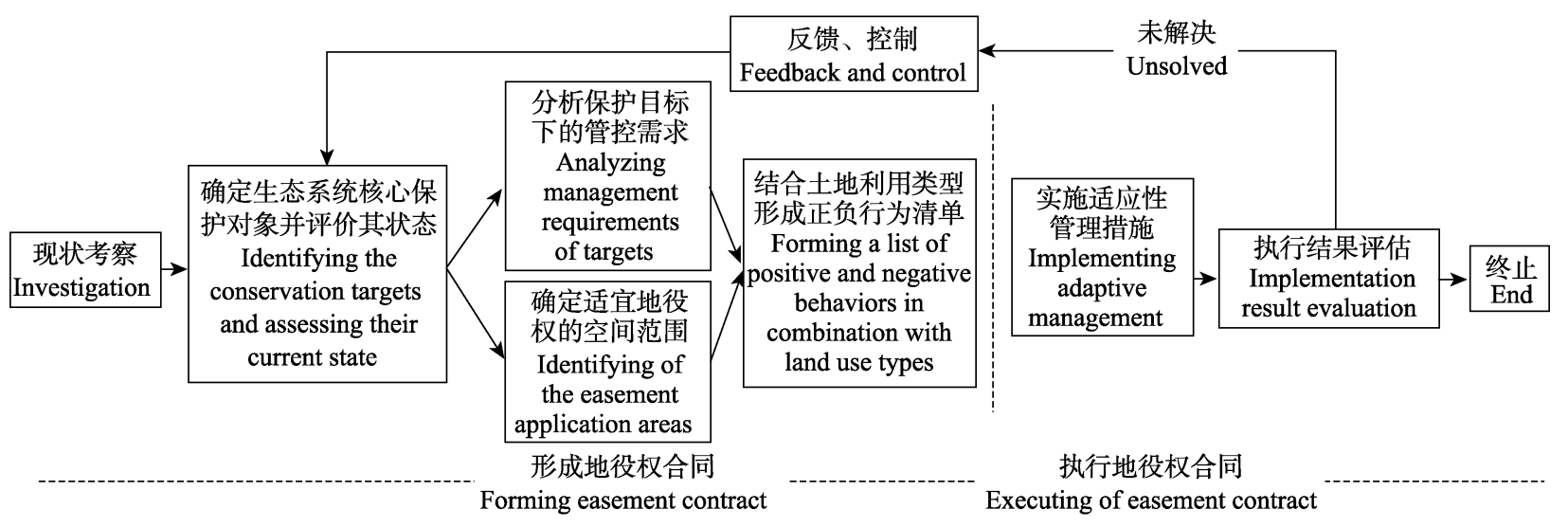

图1 以地役权制度为基础的适应性管理框架

Fig. 1 Adaptive management framework based on conservation easement

借助政策设计, 建立市场化、多元化的生态补偿机制, 构建多元利益共同体, 形成保护合力, 并用法律法规保障

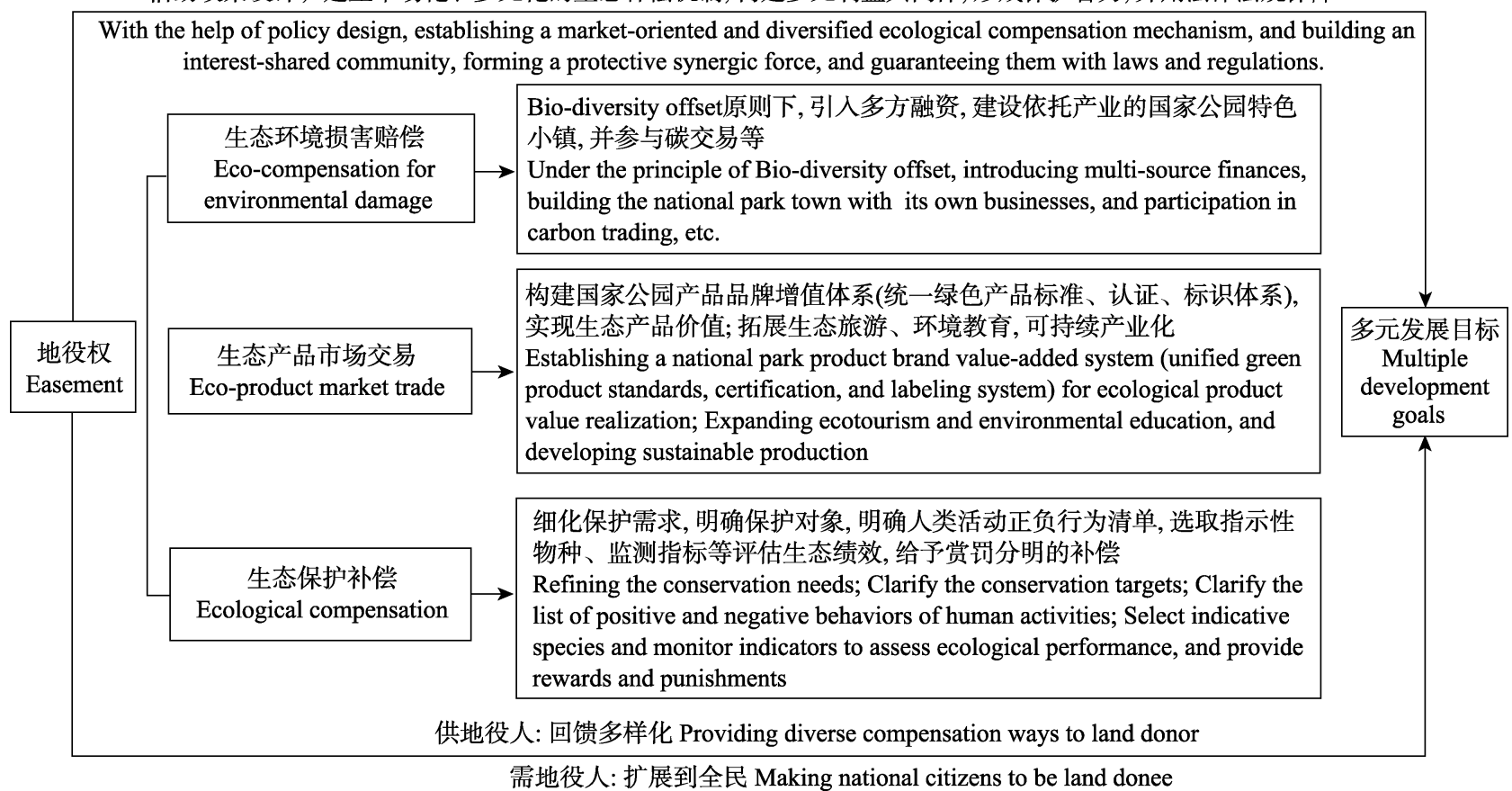

图2 结合我国实际的地役权制度生态补偿方案的设计思路。Biodiversity-offset即生物多样性中和, 主要是指工程项目等的 实施在采取一定的手段后对生态系统多样性的影响非负。

Fig. 2 Technical route for the ecological compensation mechanism based on easement policy in China biodiversity. Biodiversityoffset: after certain measures, the impact of the engineering projects on the ecosystem diversity can not be negative.

场化、多元化的生态补偿机制”, 以及“构建社区发 展协调制度” 的要求，本研究的制度设计思路如图2 所示, 要鼓励多元参与, 构建利益共同体, 形成保 护合力。

\section{3 研究方法}

本研究主要采取文献查阅、半结构式访谈和问 卷调查等方法。除分析地役权、国家公园体制制度 外, 重点对国家公园的生态系统(于明坚等, 2001;
宋凯等, 2011; 钱海源等, 2018)、生物多样性(马建忠 等, 2010; 杨沛芳, 2012; 韩璐等, 2015)和生态保护 (万本太, 2008)的基本情况进行文献分析，作为制度 设计的基础。

半结构式访谈是介于完全开放式和结构式访 谈之间的一种访谈方式。本研究调研过程中主要对 焦点人物和原住民进行访谈。其中焦点人物访谈主 要针对村干部(目的是获得社区集体信息)、政府职 
能部门的重点人物(保护区管理机构的相关干部 等)。访谈的主要目的是了解受访者利益诉求与保护 需求之间的相关性, 为正负行为清单的制定以及生 态补偿方案的设计做准备。问卷调查主要针对社区 原住民的基本生产和生活情况, 了解其受教育水 平、生计手段和收入水平等基本信息。

\section{4 案例地点的选取}

本研究主要针对钱江源国家公园体制试点区 (以下简称“钱江源国家公园”), 钱江源国家公园处 我国东部人口密集、集体林地比例较大的区域, 具 有实施保护地役权的典型性。钱江源国家公园包括 了浙江开化县苏庄、长虹、何田、齐溪共 4 个乡镇, 涉 及人口 9,744 人(截至2014年底)。国有土地和集体所 有土地分别占 $20.4 \%$ 和 $79.6 \%$ 。国家公园的主要问题 是由于道路修建、经济林种植和村镇阻隔等因素造 成的森林生态系统碎片化。试点区内原住民具有保 护生态环境的良好传统，例如当地仍保留着“封山 节”、“敬鱼节”等民俗文化活动; 珍稀的白颈长尾雉 (Syrmaticus ellioti)等野生动物与当地的采油茶等农 事活动形成了人地平衡关系。

\section{2 政策设计的基础以及实施步骤}

\section{1 原住民的利益诉求分析}

社区调研是制度设计的基础。通过对国家公园 范围内重点村落的调查了解整个试点区内原住民
生产、生活的基本情况, 如表1所示。调研发现, 社 区人口老龄化、村庄空心化问题严重，户籍人口多 但常住人口少，并且以老年人、哺乳期妇女以及儿 童为主。

本研究认为差异化的人群应平等地享受到国 家公园建设带来的福利，有必要分析原住民对国家 公园补偿的诉求，如表2所示。调研发现不同人群的 补偿诉求差别较大: 60 岁以上的人群主要希望改善 养老和医疗的基础设施条件和提高社区服务水平; 有劳动能力的青壮年更偏好于增加技能培训和就 业机会; 有孩子的家庭希望社区提供良好的教育。

\section{2 构建适应性管理框架, 形成地役权制度}

适应性管理框架主要包括：细化保护需求，确 定适宜实施地役权的标准和空间范围，制定正负行 为清单并确定监测方法。

(1)细化保护需求。主要的操作步骤包括: 明确 保护对象(主要指环境本底、生态系统、水质和生态 系统服务等), 细化保护对象的管理需求(重要区域 细化到林班尺度), 确定其与原住民的生产、生活行 为之间的关系。具体到钱江源国家公园，基于区域内 生态系统和生物多样性的监测基础和本底调查情 况, 确定了以低海拔中亚热带常绿阔叶林生态系统以 及相关珍稀物种和水源地为主的保护对象，以及重要 保护动物的栖息地活动范围不缩小的保护目标(祝 燕等, 2008; 赖江山等, 2010; 斯幸峰和丁平, 2014)。

表1 钱江源国家公园重点村落的基本情况

Table 1 Basic information of key villages in Qianjiangyuan National Park

\begin{tabular}{|c|c|c|c|c|c|}
\hline $\begin{array}{l}\text { 乡镇 } \\
\text { Town }\end{array}$ & $\begin{array}{l}\text { 自然村 } \\
\text { Natural village }\end{array}$ & $\begin{array}{l}\text { 人口 } \\
\text { Population }\end{array}$ & $\begin{array}{l}\text { 分区 } \\
\text { Zone }\end{array}$ & $\begin{array}{l}\text { 主要产业 } \\
\text { Major industry }\end{array}$ & $\begin{array}{l}\text { 核心保护对象 } \\
\text { Core conservation targets }\end{array}$ \\
\hline \multirow[t]{7}{*}{ 苏庄 Suzhuang } & 龙潭口 Longtankou & 118 & 核心保护区 Core protected zone & $\begin{array}{l}\text { 茶叶、油茶 } \\
\text { Tea and sasanqua }\end{array}$ & $\begin{array}{l}\text { 生态系统、水源 } \\
\text { Ecosystem and water sources }\end{array}$ \\
\hline & 东山 Dongshan & 106 & $\begin{array}{l}\text { 生态保育区 } \\
\text { Ecological conservation zone }\end{array}$ & $\begin{array}{l}\text { 茶叶、油茶 } \\
\text { Tea and sasanqua }\end{array}$ & $\begin{array}{l}\text { 生态系统、水源 } \\
\text { Ecosystem and water sources }\end{array}$ \\
\hline & 外长坑头 Waichangkengtou & 80 & 核心保护区 Core protected zone & $\begin{array}{l}\text { 茶叶、农作物 } \\
\text { Tea and crops }\end{array}$ & 生态系统 Ecosystem \\
\hline & 内长坑头 Neichangkengtou & 6 & 核心保护区 Core protected zone & $\begin{array}{l}\text { 茶叶、农作物 } \\
\text { Tea and crops }\end{array}$ & 生态系统 Ecosystem \\
\hline & 青安塘 Qing’antang & 24 & $\begin{array}{l}\text { 生态保育区 } \\
\text { Ecological conservation zone }\end{array}$ & 茶叶 Tea & 生态系统 Ecosystem \\
\hline & 冲凹 Chong’ao & 6 & 核心保护区 Core protected zone & $\begin{array}{l}\text { 茶叶、养蜂 } \\
\text { Tea and beekeeping }\end{array}$ & 生态系统 Ecosystem \\
\hline & 岭里头 Linglitou & 2 & 核心保护区 Core protected zone & & 生态系统 Ecosystem \\
\hline 齐溪 Qixi & 大鲍山 Dabaoshan & 79 & 核心保护区 Core protected zone & & 生态系统 Ecosystem \\
\hline 长虹 Changhong & 河滩 Hetan & 99 & $\begin{array}{l}\text { 生态保育区 } \\
\text { Ecological conservation zone }\end{array}$ & $\begin{array}{l}\text { 茶叶、农作物 } \\
\text { Tea and crops }\end{array}$ & $\begin{array}{l}\text { 生态系统、水源 } \\
\text { Ecosystem and water sources }\end{array}$ \\
\hline
\end{tabular}


(2)确定适宜实施地役权的空间范围。结合森林 资源二类调查、动物栖息地范围和活动规律, 在地 图上标识有差异化保护需求的区域。尽管国家公园 强调的是生态系统的完整性保护，但考虑到政策执 行成本, 确定地役权实施范围时需要有所侧重。应 重点关注集体所有的土地和重点保护对象有重叠 的区域，明确有利于不同类型的林相正向演替的管 控措施(比如通过建立生态廊道保持生态系统完整 性), 并在此区域重点开展监测和管制。在自然资源
确权基础上，结合土地权属，绘制出适宜地役权的 空间范围，同时确定原住民可参与的方式。最后， 综合多方面因素(如生态系统完整性、水源地代表性 和跨界管理问题等)節选了浙江省开化县长虹乡霞 川村作为试点开展工作。

(3)制定正负行为清单。在考虑土地类型的差异 及其对应的人类行为的基础上，形成原住民的正负 行为清单(举例如表3所示), 并将其作为空间上的正 负行为准则。其中，土地类型包括林地、耕地、园

表2 钱江源国家公园原住居民对国家公园补偿的诉求

Table 2 Compensation requirements of local citizens from the Qianjiangyuan National Park

\begin{tabular}{|c|c|c|}
\hline 直接补贴 Direct subsidy & 社会福利 Social welfare & 生计带动 Income increase \\
\hline $\begin{array}{l}\text { 液化气补贴 } \\
\text { Subsidies for liquefied gas } \\
\text { 景区开发补贴 } \\
\text { Subsidies for scenic spot } \\
\text { development } \\
\text { 生态公益林补贴 } \\
\text { Subsidies for ecological forest } \\
\text { 基本农田补贴 } \\
\text { Subsidies for basic farmland } \\
\text { 地役权限制和鼓励行为补贴 } \\
\text { Subsidies for the restrictions and } \\
\text { encouragements of easement }\end{array}$ & $\begin{array}{l}\text { 老人、残疾人补贴 } \\
\text { Subsidies for old and disabled people } \\
\text { 安装有线、无线网络 } \\
\text { Installation of wired or wireless network } \\
\text { 丰富娱乐活动 } \\
\text { Diversified activities for entertainment } \\
\text { 生产生活基础设施水平提高(垃圾处理、污水排放处理、 } \\
\text { 修路等) } \\
\text { Improvement of production and living infrastructure } \\
\text { (waste treatment, waste water treatment, road } \\
\text { construction, etc.) } \\
\text { 医疗、教育等公共服务水平提高 } \\
\text { Improvement of public service, including medical care } \\
\text { and education, etc. }\end{array}$ & $\begin{array}{l}\text { 茶叶、油茶等国家公园品牌产品 } \\
\text { Tea, sasanqua and other products with National park } \\
\text { brand } \\
\text { 农家乐、农机培训、保护地管理、对森林资源开发 } \\
\text { 利用、发展生态旅游等 } \\
\text { Hotels, agricultural machinery training, protected area } \\
\text { management, utilization of forest resources, and } \\
\text { ecotourism, etc. }\end{array}$ \\
\hline
\end{tabular}

\section{表3 原住民正负行为清单(耕地部分) ${ }^{\mathbf{a}}$}

Table 3 Positive and negative behavior list of local citizens (agricultural lands) ${ }^{\mathrm{a}}$

\begin{tabular}{|c|c|c|c|}
\hline $\begin{array}{l}\text { 保护对象 } \\
\text { Conservation targets }\end{array}$ & $\begin{array}{l}\text { 正/负 } \\
\text { Positive or negative }\end{array}$ & $\begin{array}{l}\text { 具体行为 } \\
\text { Specific actions }\end{array}$ & $\begin{array}{l}\text { 参与方式 } \\
\text { Participant measures }\end{array}$ \\
\hline \multirow{4}{*}{$\begin{array}{l}\text { 环境本底、水源地和 } \\
\text { 生态系统服务 } \\
\text { Environmental } \\
\text { background, water } \\
\text { source and ecosystem } \\
\text { services }\end{array}$} & $\begin{array}{l}\text { 禁止 } \\
\text { Forbidden }\end{array}$ & $\begin{array}{l}\text { 使用未经批准的化肥、农药、除草剂 } \\
\text { Use of unapproved fertilizers, pesticides, and herbicides }\end{array}$ & 个人 Individual \\
\hline & & $\begin{array}{l}\text { 使用未经发酵处理的粪便作为肥料 Use of non-fermented manure } \\
\text { 秸秆焚烧 Straw burning }\end{array}$ & $\begin{array}{l}\text { 个人 Individual } \\
\text { 个人 Individual }\end{array}$ \\
\hline & $\begin{array}{l}\text { 鼓励 }^{\mathrm{b}} \\
\text { Encouraged }^{\mathrm{b}}\end{array}$ & 合理套种, 合理密植 Reasonable inter-planting and compact planting & $\begin{array}{l}\text { 集体/个人 } \\
\text { Collective /individual }\end{array}$ \\
\hline & & 立体农业 Stereoscopic agriculture & 个人 Individual \\
\hline \multirow{3}{*}{$\begin{array}{l}\text { 物种、种群、群落和 } \\
\text { 生态系统 } \\
\text { Species, populations, } \\
\text { communities and } \\
\text { ecosystems }\end{array}$} & $\begin{array}{l}\text { 禁止 } \\
\text { Forbidden }\end{array}$ & $\begin{array}{l}\text { 驱赶、捕捉进入耕地的野生动物 } \\
\text { Expelling or catching wild animals that entering cultivated land }\end{array}$ & 个人 Individual \\
\hline & & $\begin{array}{l}\text { 以围栏、栅栏等形式明确隔离耕地和自然环境 } \\
\text { Clear separation between cultivated land and natural environment by using } \\
\text { the fences, etc. }\end{array}$ & 个人 Individual \\
\hline & $\begin{array}{l}\text { 鼓励 } \\
\text { Encouraged }\end{array}$ & $\begin{array}{l}\text { 以本土植物形成天然的隔离林带 } \\
\text { Using local plants as the fence between natural environment and plantation }\end{array}$ & $\begin{array}{l}\text { 集体/个人 } \\
\text { Collective /individual }\end{array}$ \\
\hline $\begin{array}{l}\text { 文化遗产等原真性 } \\
\text { Originality of cultural } \\
\text { heritage, etc. }\end{array}$ & $\begin{array}{l}\text { 鼓励 }^{\mathrm{b}} \\
\text { Encouraged }^{\mathrm{b}}\end{array}$ & $\begin{array}{l}\text { 保留传统农耕文化 Preserving traditional farming culture } \\
\text { 适度发展耕地景观、发展生态旅游和环境教育 } \\
\text { Moderating development of cultivated land landscape, ecotourism and } \\
\text { environmental education }\end{array}$ & $\begin{array}{l}\text { 个人 Individual } \\
\text { 集体 Collective }\end{array}$ \\
\hline
\end{tabular}

a 对于原住民正负行为清单, 有必要结合国家公园功能分区进行细化, 在实践阶段进一步调整, 文章内不作更多探讨; ${ }^{b}$ 核心区内, 鼓励耕地 退出或者弃收。

${ }^{a}$ For the list of the local citizens' positive and negative behaviors, it is necessary to be adjusted considering the national park functions, which is not discussed in this paper; ${ }^{\mathrm{b}}$ In the core protected area, farmland withdrawal and giving up collecting corps are encouraged. 
地、宅基地和水源地。其中宅基地的行为清单主要 对应的是原住民的日常生活行为。

(4)确定监测指标和方法。参考森林生态系统生 物多样性监测和评估规范(LY/T 2241-201), 确定表 征生物多样性保护效果的监测指标以及指示性物 种的监测方法(选取有代表性的白颈长尾雉和黑鹿 (Muntiacus crinifrons)为指示性物种)(表4)。

\section{3 地役权合同的形成和执行}

以适应性管理为基础, 结合当前我国生态补偿 政策，形成地役权合同并执行，具体包括:

(1)制定保护效果的评价方法和补偿标准。为防 止传统生态补偿政策一刀切的现象, 有必要对原住 民参与的保护行为进行生态绩效评价, 并给予补 偿。地役权保护效果的评价包括三个方面, 分别是: 村民正负行为的遵守情况、客观监测指标的改进情 况(对部分指标, 需要专业科研团队的支持, 并且赋 予其在重大项目和政策执行方面的一票否决权)和 其他能力建设要求(比如制度建设等)。运用风险控 制理论和生态足迹的原理, 结合原住民生产、生活 行为的频率和行为对生态系统的影响, 参考东部地 区物价水平和地方政府财政承受力, 结合经济学中 的机会成本法和最小受偿意愿法等, 本着“论功行 赏、赏罚分明” 的原则, 量化正负行为的价值, 以此 为基础制定差异化的生态补偿标准。另外, 地役权 执行的形式与集体以及个人的参与方式有关系，也 与土地类型(林地、耕地、园地、宅基地和水源附近 土地)有关，具体操作层面可以结合实际情况调整。

考虑当前我国农村社会的治理结构, 基于调研 结果和其他保护地经验(如浙江杭州良渚文化遗址
生态补偿的成功经验)，地役权保护效果评价操作 思路如下：由国家公园和村集体签订保护协议，并 明确监管方法; 村集体与原住民签订协议，由各村 自行决定地役权补偿资金的用途、分配比例，促进 村民自治; 经国家公园管理机构全程监督认可并经 第三方定期评估考核确认各村保质保量完成协议 区域内的保护任务后，为村集体颁发补偿金。

主要根据以下标准体系打分(表5), 方法如下: 总计分 $=$ 行为计分个人 $\times 30 \%+$ 行为计分集体 $\times 20 \%+$ 生态指标计分 $\times 30 \%+$ 社区能力建设计分 $\times 20 \%$

评价满分为 100 分，按最后所得分值和补偿基 数计算每年度实际应该获得的地役权直接补偿金 额，计算公式如下:

地役权直接补偿金额 $=$ 补偿基数 $\times$ 总计分 $/ 100$ 其中, 补偿基数主要根据原住民的收入水平、地方 政府财政承受能力和融资情况确定。具体某一个村 的补偿基准，需要根据行政村(社区)人口、面积、生 态敏感度等因素通过协商确定。

结合实际，地役权合同中对原住民正负行为的 补偿金额并不是直接从经济价值角度核算，而是在 确定各村补偿基数后，参考正负行为的频率和强度 确定的。对于极端负面行为(如盗猎), 一票否决其获 奖励机会; 对于正面行为，按照评估结果占总分的 比例给予相应的补偿。

其中，村民行为和村集体的总分是由第三方根 据有劳动力的原住民每年实际履行清单情况评估 所得的平均数来确定。补偿金额设定上限和下限, 其中下限为遵守正负行为获得的直接补偿和日常 管护运营经费; 上限包括下限和间接补偿(生态岗

表4 钱江源国家公园森林生态系统中野生动植物多样性的部分监测指标

Table 4 Part of the monitoring indicators for the diversity of wild animals and plants in the Qianjiangyuan National Park forest ecosystem

\begin{tabular}{|c|c|c|c|}
\hline \multicolumn{2}{|l|}{ 分类 Category } & 监测指标/方式 Monitoring indicators/methods & \multirow{2}{*}{$\begin{array}{l}\text { 周期 Period } \\
\text { 每年2次 } \\
\text { Twice a year }\end{array}$} \\
\hline $\begin{array}{l}\text { 野生植物监测 } \\
\text { Wild plant } \\
\text { monitoring }\end{array}$ & $\begin{array}{l}\text { 种类 Species } \\
\text { 变化 Changes }\end{array}$ & $\begin{array}{l}\text { 物种名称、数量 Name and number of species } \\
\text { 无人机监测各种植被类型面积和高度的变化 } \\
\text { Changes in areas and height of different plant types by using unmanned aerial vehicle } \\
\text { (UVA) monitoring }\end{array}$ & \\
\hline $\begin{array}{l}\text { 野生动物监测 } \\
\text { Wild animal } \\
\text { monitoring }\end{array}$ & $\begin{array}{l}\text { 种类 Species } \\
\text { 种群 Populations }\end{array}$ & $\begin{array}{l}\text { 物种名称、数量 Name and number of species } \\
\text { 分布格局 Distribution pattern } \\
\text { 物种相对多度指数 Specie relative abundance index (RAI) }\end{array}$ & $\begin{array}{l}\text { 每年2次 } \\
\text { Twice a year } \\
\text { 长期 Long-term }\end{array}$ \\
\hline \multicolumn{2}{|c|}{ 资源利用 Resource utilization } & $\begin{array}{l}\text { 乔、灌、草植物的名称、采集地点、采集数量、利用部位、用途、交易方式 } \\
\text { Names of arbors, shrubs and herbs, collecting location and numbers, available parts, } \\
\text { using ways and trading ways }\end{array}$ & $\begin{array}{l}\text { 每月1次 } \\
\text { Once a month }\end{array}$ \\
\hline \multicolumn{2}{|c|}{ 人为干扰 Human disturbance } & 干扰方式和强度 Disturbance mode and intensity & 每年1次 Once a year \\
\hline
\end{tabular}


表5 钱江源国家公园地役权实施评价体系

Table 5 Evaluation system of the easement in Qianjiangyuan National Park

\begin{tabular}{|c|c|c|c|c|}
\hline $\begin{array}{l}\text { 评价内容 } \\
\text { Evaluation items }\end{array}$ & $\begin{array}{l}\text { 评价主体 } \\
\text { Evaluation subjects }\end{array}$ & $\begin{array}{l}\text { 权重 } \\
\text { Weight }\end{array}$ & $\begin{array}{l}\text { 评价周期 } \\
\text { Evaluation period }\end{array}$ & $\begin{array}{l}\text { 评价目标 } \\
\text { Evaluation targets }\end{array}$ \\
\hline $\begin{array}{l}\text { 社区个人正负行为 } \\
\text { Positive and negative individual } \\
\text { behaviors in the community }\end{array}$ & $\begin{array}{l}\text { 集体对个人评估 } \\
\text { The community evaluates individuals }\end{array}$ & $30 \%$ & $\begin{array}{l}\text { 每年 } \\
\text { Once a year }\end{array}$ & \multirow{2}{*}{$\begin{array}{l}\text { 地役权合同中正负行为的遵守情 } \\
\text { 况 } \\
\text { Compliance to the positive and } \\
\text { negative behaviors listed in the } \\
\text { easement contract }\end{array}$} \\
\hline $\begin{array}{l}\text { 社区集体正负行为 } \\
\text { Positive and negative behaviors in the } \\
\text { community }\end{array}$ & $\begin{array}{l}\text { 国家公园管理机构对社区集体评估 } \\
\text { National park management agency } \\
\text { evaluates the community }\end{array}$ & $20 \%$ & $\begin{array}{l}\text { 每年 } \\
\text { Once a year }\end{array}$ & \\
\hline $\begin{array}{l}\text { 常规监测指标评价 } \\
\text { Routine monitoring indicator evaluation }\end{array}$ & $\begin{array}{l}\text { 第三方评估 } \\
\text { The third-party evaluation }\end{array}$ & $30 \%$ & $\begin{array}{l}\text { 每年 } \\
\text { Once a year }\end{array}$ & $\begin{array}{l}\text { 生态保护效果 } \\
\text { Ecological conservation effects }\end{array}$ \\
\hline $\begin{array}{l}\text { 社区能力建设 } \\
\text { Community capacity improving }\end{array}$ & $\begin{array}{l}\text { 第三方评估 } \\
\text { The third-party evaluation }\end{array}$ & $20 \%$ & $\begin{array}{l}\text { 每年 } \\
\text { Once a year }\end{array}$ & $\begin{array}{l}\text { 社区能力建设效果 } \\
\text { Community capacity improvement }\end{array}$ \\
\hline
\end{tabular}

位、基础设施改善、公共福利改善、特许经营获利、 其他社会渠道捐赠等)。

补偿上限 $=$ 补偿下限 + 间接补偿

(2)形成地役权合同并实施。地役权合同包括保 护目标、监测方法、考核方法、供役地人、需役地 人、供役地范围、期限以及供役地人与需役地人的 权利和义务等内容。其中, 地役权合同的签订主要 由乡镇政府或国家公园管委会推动，需配套建立考 核目标体系、考核办法、奖惩机制。

(3)引入社会力量, 丰富地役权。社会力量(包括 营利和非营利性质的社会组织)的引入是间接补偿 的重要环节。营利组织主要参与构建国家公园产品 品牌增值体系(品牌增值体系包括产品和产业发展 指导体系、产品质量标准体系、产品认证体系和品 牌管理推广体系等) (苏杨等, 2018)。该体系可以将 资源环境的优势转化为产品品质的优势并通过品 牌平台固化, 在保护地友好和社区友好的约束下实 现单位产品价值的提升。借助特许经营的形式, 激 励原住民参与保护, 鼓励地方龙头企业参与, 培养 可持续的产业, 将保护和品牌结合, 并惠及社区。 钱江源国家公园产品品牌增值体系的产品包括开 化县已经有扶持基础但缺少品牌效应的茶叶、油 茶、民宿等。可以通过引入绿色融资, 建设国家公 园特色小镇, 并构建品牌增值体系, 促进三产融 合。非营利组织对解决跨行政区管理有助力, 可以 作为地役权合同的签订方, 规定参与管理的跨界区 和国家公园遵循同样科学的管理方法, 促进生态系 统完整性的保护。

\section{3 政策实践和保障}

适应性管理的理念已经被学术界普遍认可, 但
是实践中却少有成功案例。我国自然资源的适应性 管理大部分停留在理论性论述和框架研究阶段(徐 广才等, 2013)。钱江源国家公园借助依托地役权制 度的适应性管理，可以解决对不同权属的土地进行 科学、统一管理的问题, 并通过生态补偿等机制鼓 励原住民参与保护，实现绿色发展。

下面就制度实践以及保障展开讨论。

\section{1 制度实践}

操作层面上，“钱江源国家公园适应性管理办 法”的推进从地役权开始。浙江省开化县2018年4月 颁布了《关于印发钱江源国家公园集体林地地役权 改革实施方案》 (http://www.kaihua.gov.cn/art/ 2018/4/4/art_1387096_1544.html)。该方案在不必赎 买集体土地和进行生态移民的前提下，可快速推进 地役权改革且成本较低, 达到了国家公园自然资源 统一管理的基本要求, 为科学地实施适应性管护奠 定了基础。但该方案本质上看还是属于传统意义的 生态补偿, 没有解决种植大户承包问题、跨界问题 和绿色发展问题，并且缺少体制机制创新。而本研 究的制度设计, 和开化县现行地役权方案衔接, 率 先以试点的形式展开政策尝试。除了可以解决上述 问题外，还设计了对耕地、园地、宅基地和水源地 的适应性管理办法和多元化的生态补偿方案。

另外，需要指出社区是重要的参与方，其自然 资源管理的目标和模式要符合国家公园的管控要 求。对操作难度较大、专业化程度较高、对生态和 环境产生干扰的活动，必须由国家公园专职技术人 员完成, 对于一定规模的项目须进行专业的生态环 境影响评价。

\section{2 制度保障}

完善的法律法规和清晰的治理结构是制度执 
行的保障。需要制定“钱江源国家公园适应性管理 办法” 并作为其专项管理办法纳入 “钱江源国家公园 管理条例”。明确适应性管理的操作步骤, 出台关于 地役权的地方性法规，规避其法律法规缺失的问 题。要制定“特许经营管理条例”和“国家公园产品品 牌管理办法”, 以特许经营合同的形式提出加入国 家公园品牌增值体系的标准和办法。考虑到生态公 益等岗位更受社区欢迎并对国家公园有贡献，特许 经营中要明确企业需要吸纳的原住民的具体比例 或人数(优先保障核心区和生态保育区)。

另外, 适应性管理的目标是服务于国家公园统 一、规范的管理决策, 涉及国家公园管理方、专家 学者、专业技术人员和其他的利益相关方(社区、公 众、企业、非政府组织和第三方机构等)。需要充分 考虑各利益相关方的诉求，因此要借助“国家公园 适应性管理办法”的制定, 明确各利益相关方的权 责利，特别是不同渠道的资金整合和角色分配。充 分协商后，使地役权获得社区支持，利益共同体得 以重构和再平衡, 并达成一致的管理目标。其中最 大的难点是监测的执行、监测指标的检验和评估体 系的建立。它们需要较长的时间及大量资金投入, 需要探索性试验并考虑长期的成本和收益, 特别是 试点期间对难以操作的监测指标进行调整。因此, 管理需要设计动态机制以及反馈机制, 并且允许项 目的执行有灵活性，以保障其可操作性。

\section{4 结论}

钱江源国家公园通过提高集体林地生态补偿 的标准，与社区签订保护地役权合同，保证原住民 生产、生活符合国家公园管理要求, 以较低的成本 使自然资源的统一管理得以快速推进。同时, 为避 免“一刀切”的模式, 在充分考虑各利益相关方诉求 的基础上，率先以试点形式探索地役权制度，以实 现更科学的适应性管理模式, 即本研究方案。试点 区探索兼顾了保护和发展, 控制了移民数量并且在 跨省合作方面展开了尝试, 为社区设计了绿色发展 的技术路线, 即构建国家公园产品品牌增值体系作 为间接补偿的主要措施之一, 具有创新性和全国示 范意义。

这样的制度设计具有一定的普适性，可以应用 于以下两类区域: 一类是全国同类的试点区(比如 生态保护与社区发展矛盾突出的武夷山国家公园
体制试点区、社区原住民协调困难的东北虎豹国家 公园体制试点区); 另一类是和钱江源试点区在同 一生态系统内、跨行政区域的江西、安徽地段。上 述技术路线适用于山水林田湖草的一体化管理，除 去文中提到的森林生态系统，该制度如何用于湿 地、草原等生态系统, 有待结合实际情况展开深入 研究。

\section{参考文献}

Birgé HE, Allen CR, Garmestani AS, Pope KL (2016) Adaptive management for ecosystem services. Journal of Environmental Management, 183, 343-352.

Han L, Wu HM, Cheng BD, Wen YL (2015) South Africa's biodiversity conservation and its enlightenment to China: A case study of Kruger National Park. World Forestry Research, 28(3), 75-79. (in Chinese with English abstract) [韩 璐, 吴红梅, 程宝栋, 温亚利 (2015) 南非生物多样性保 护措施及启示一以南非克鲁格国家公园为例. 世界林 业研究, 28(3), 75-79.]

He SY, Su Y, Luo HN, Wang L (2017) Research of management methodology in protected area based on itemised conservation requirements-Supporting construction of China pilot national park's construction. Environmental Protection, 45(Z1), 50-57. (in Chinese with English abstract) [何思源, 苏杨, 罗慧男, 王蕾 (2017) 基于细化保护需求的保护地 空间管制技术研究——中国国家公园体制建设为目标. 环境保护, 45(Z1), 50-57.]

Hou XY, Yin YT, Ding Y (2011) An overview and prospects for grassland adaptive Management in China. Acta Prataculturae Sinica, 20, 262-269. (in Chinese with English abstract) [侯向阳, 尹燕亭, 丁勇 (2011) 中国草原适应性管理研 究现状与展望. 草业学报, 20, 262-269.]

Lai JS, Mi XC, Ren HB, Ma KP (2010) Numerical classifycation of associations in subtropical evergreen broad-leaved forest based on multivariate regression trees-A case study of $24 \mathrm{hm}^{2}$ Gutianshan forest plot in China. Chinese Journal of Plant Ecology, 34, 761-769. (in Chinese with English abstract) [赖江山，米湘成，任海保，马克平 (2010) 基于 多元回归树的常绿阔叶林群从数量分类——古田山 24 公顷森林样地为例. 植物生态学报, 34, 761-769.]

Ma JZ, Yang GH, Han MY, Zhang ZM, Yang ZJ, Chen B (2010) Study on approaches of biodiversity conservation and planning for Meili Snow Mountain National Park. Forest Inventory \& Planning, 35, 119-123. (in Chinese with English abstract) [马建忠, 杨桂华, 韩明跃, 张志明, 杨子江, 陈鄚 (2010) 梅里雪山国家公园生物多样性保护规划方 法研究. 林业调查规划, 35, 119-123.]

Murray C, Marmorek DR(2004) Adaptive management: A spoonful of rigour helps the uncertainty go down. In: Proceedings of the 16th Annual Society for Ecological Restoration Conference, Victoria BC. 
Ma KP (2009) A Brief Course on Conservation Biology, 4th edn. Higher Education Press, Beijing. (in Chinese) [马克平 (2009) 保护生物学简明教程, 第4版. 高等教育出版社, 北京.]

Qian HY, Zhang TT, Chen SW, Wu DH, Wu CP, Yuan WG, Jin Y, Yu MJ (2018) Community structures and bio-diversities of broad-leaved forest and two types of plantations in Gutianshan National Nature Reserve, Zhejiang Province. Guihaia, 38, 1371-1381. (in Chinese with English abstract) [钱海源, 张田田, 陈声文, 巫东豪, 吴初平, 袁位高, 金 毅, 于明坚 (2018) 古田山自然保护区阔叶林与两种人 工林的群落结构和生物多样性. 广西植物. 38, 1371-1381.]

Si XF, Ding P (2014) Camera trap survey on population dynamics of mammals and birds in Gutianshan forest dynamics plot, eastern China. Biodiversity Science, 22, 819-822. (in Chinese with English abstract) [斯幸峰, 丁平 (2014) 古田 山森林动态监测样地内鸟兽种群动态的红外相机监测. 生物多样性, 22, 819-822.]

Song K, Mi XC, Jia Q, Ren HB, Bebber D, Ma KP (2011) Variation in phylogenetic structure of forest communities along a human disturbance gradient in Gutianshan forest. Biodiversity Science, 19, 190-196. (in Chinese with English abstract) [宋凯, 米湘成, 贾琪, 任海保, Dan Bebber, 马克 平 (2011) 不同程度人为干扰对古田山森林群落谱系结 构的影响. 生物多样性, 19, 190-196.]

Su Y, Wang L (2015) Relative concepts, policy background and technological difficulty of pilot national park system in China. Environmental Protection, 43(14), 17-23. (in Chinese with English abstract) [苏杨, 王蕾 (2015) 中国国 家公园体制试点的相关概念、政策背景和技术难点. 环境 保护, 43(14), 17-23.]

Su Y, He SY, Wang YF, Wei Y (2018) Policy Research on the Development of China's Pilot National Parks. Social Sciences Academic Press, Beijing. (in Chinese) [苏杨, 何思 源, 王宇飞, 魏钰 (2018) 中国国家公园体制建设研究. 社会科学文献出版社, 北京.]

Tang XH (2014) Construction of the Natural Resources Conservation Easements in China. PHD dissertation, Jilin University, Changchun. (in Chinese with English abstract) [唐孝辉 (2014) 我国自然资源保护地役权制度构建. 博 士学位论文, 吉林大学, 长春.]

Wan BT (2008) Building national parks to promote regional ecological protection and harmonious development of economy and society. Environmental Protection, 21, 35-37. (in Chinese) [万本太 (2008) 建设国家公园, 促进区域生态
保护和经济社会协调发展. 环境保护, 40(21), 35-37.]

Williams BK, Allen CR, Pope KL, Fontaine JJ (2011) Adaptive management of natural resources framework and issues. Journal of Environmental Management, 92, 1346-1353.

Xu GC, Kang MY, Shi YJ (2013) A review of adaptive management research on natural resources. Journal of Natural Resources, 28, 1797-1807. (in Chinese with English abstract) [徐广才, 康慕谊, 史亚军 (2013) 自然资源适应性管理 研究综述. 自然资源学报, 28, 1797-1807.]

Yang PF (2012) Biodiversity monitoring of Meili Snow Mountain National Park. Forest Inventory \& Planning, 37, 108-111. (in Chinese with English abstract) [杨沛芳 (2012) 梅里雪山国家公园生物多样性监测. 林业调查规划, 37, 108-111.]

Yang RJ, Fu BJ, Liu GH, Ma KM (2004) Principles and methods of sustainable management of ecosystem. Chinese Journal of Ecology, 23, 103-108. (in Chinese with English abstract) [杨荣金, 傅伯杰, 刘国华, 马克明 (2004) 生态 系统可持续管理的原理和方法. 生态学杂志, 23 , 103-108.]

Ye GF, You LH, Lu CY, Lin WX, Luo MJ, Tan FL (2015) Global climate change and adaptive management of forest ecosystem. World Forestry Research, 28(1), 1-6. (in Chinese with English abstract) [叶功富, 尤龙辉, 卢昌义, 林武星, 罗美娟, 谭芳林 (2015) 全球气候变化及森林生 态系统的适应性管理. 世界林业研究, 28(1), 1-6.]

Yu MJ, Hu ZH, Yu JP, Ding BY, Fang T (2001) Forest vegetation types in Gutianshan Natural Reserve in Zhejiang. Journal of Zhejiang Agricultural University(Agriculture and Life Sciences), 27, 375-380. (in Chinese with English abstract) [于明坚, 胡正华, 余建平, 丁炳扬, 方腾 (2001) 浙江古田山自然保护区森林植被类型. 浙江大学学报(农 业与生命科学版), 27, 375-380.]

Zhu Y, Zhao GF, Zhang LW, Shen GC, Mi XC, Ren HB, Yu MJ, Chen JH, Chen SW, Fang T, Ma KP (2008) Community composition and structure of Gutianshan forest dynamic plot in a mid-subtropical evergreen broad-leaved forest, East China. Journal of Plant Ecology (Chinese Version), 32, 262-273. (in Chinese with English abstract) [祝燕, 赵谷风, 张俪文, 沈国春, 米湘成, 任海保, 于明坚, 陈建华, 陈 声文, 方腾, 马克平 (2008) 古田山中亚热带常绿阔叶林 动态监测样地——群落组成与结构. 植物生态学报, 32 , 262-273.]

(责任编委: 李俊生 责任编辑: 时意专) 